\title{
AN AUTOMATIC EXTRACTION METHOD FOR ANTARCTIC SUBGLACIAL LAKE BASED ON RADIO ECHO SOUNDING DATA
}

\author{
D. Wang ${ }^{1,2}$, T. Feng ${ }^{1,2^{*}}$, T. Hao ${ }^{1,2}$, R. Li $^{1,2}$ \\ 1 Center for Spatial Information Science and Sustainable Development Applications, Tongji University, 1239 Siping Road, \\ Shanghai, China. \\ 2 College of Surveying and Geo-Informatics, Tongji University, 1239 Siping Road, Shanghai, China
}

KEY WORDS: Antarctica, Subglacial Lake, Automated Extraction, Radio Echo Sounding, Reflective Characteristics, Image Processing Techniques.

\begin{abstract}
:
Detection of subglacial lakes and interpretation their hydrological connectivity is of great importance to understanding the mass balance of Antarctic ice sheet. Over the past five decades, a large number of Radio Echo Sounding (RES) data has been collected in Antarctica. However, the identification of subglacial lakes based on RES data mainly relies on visual interpretation due to the lack of quantitative indicators for subglacial lakes distinguishing. To solve this problem, an automatic subglacial lakes detection method based on the reflective characteristics of B-scan echogram is proposed in this paper. Firstly, the echo strength of the original radar echogram is corrected for the dielectric attenuation and geometric spreading in the ice. Secondly, the original radar echogram is binarized to preserve the bright subglacial lake region, and the thickness of bright pixels is measured along the direction of A-scan. Thirdly, the thickness, the variance of the thickness in the neighbourhood and the corrected echo strength are used to obtain the response value for the subglacial lake. Finally, a threshold for the response value is determined to detect subglacial lakes. It is found that the proposed method can determine the location of the subglacial lake in Antarctica's Gamburtsev Province (AGAP) region with high accuracy.
\end{abstract}

\section{INTRODUCTION}

Radio Echo Sounding (RES), one of many geophysical methods, has been widely used in the detection of ice thickness, subglacial topography, and internal structure of ice sheet in Antarctica (Evans 1963). Since the discovery of the first subglacial lake using RES data, people gradually realized the importance of subglacial lakes in understanding the basal hydrological system of Antarctica (Robin et al., 1970). In the processing of RES data, subglacial lakes are recognized as the characteristics of higher echo strength, higher flatness and smoothness than other basal interfaces (Gorman and Siegert, 1999; Siegert et al., 1996), which greatly reduces the difficulty of the determination of subglacial lakes (Dowdeswell and Siegert, 2003). However, this still largely depended on visual interpretation of RES echograms (Oswald 1975; Palmer et al., 2013). Intrinsically, visual interpretation has many limitations (Ilisei et al., 2017; Ilisei et al., 2018), for example, it is usually time-consuming, and processing expertise cannot be standardized. To overcome these limitations, it is imperative to develop an automatic or semi-automatic subglacial lake identification method.

At present, most methods only use the inherent characteristics of subglacial lakes pointed out by various researchers, such as high echo strength (Creyts et al., 2014; Oswald and Robin, 1973; Wolovick et al., 2013), low slope (Bowling et al., 2019; Carter et al., 2009; Diez et al., 2019; Langley et al., 2011; Siegert 2000), and high smoothness (Carter et al., 2007; Jordan et al., 2017; Li et al., 2010; Siegert et al., 2004; Taylor et al., 2004). However, in order to further improve the identification accuracy, more identification criteria for subglacial lakes need to be developed and standardized. For example, Oswald and Gogineni (2008) proposed an abruptness criterion that can reflect the difference of signal intensity between ice-bedrock interface and ice-water interface. In addition, threshold is a key for automatic identification. At present, most of the existing methods use multiple thresholds corresponding to multiple criteria for multiple judgments to obtain the final identification result (Gifford and Agah, 2012; Oswald and Gogineni, 2008; Carter et al., 2007; Diez et al., 2019), which greatly reduces the accuracy and automation of identification.

To improve the accuracy and automation of subglacial lakes identification, this paper proposes two new criteria based on the reflective characteristics on B-scan echogram, and combines them with corrected echo strength to obtain the response value for subglacial lakes to improve the accuracy. Furthermore, only a single threshold is needed in this identification scheme to improve the automation.

\section{PROPOSED METHOD}

\subsection{Criterion 1: corrected echo strength}

In evaluation of the echo strength, we first need to implement the conversion using equation (1) (Matsuoka et al., 2010).

$$
[P]_{\mathrm{dB}}=10 \log _{10}\left([P]_{\text {Watt }}\right)
$$

where $[P]_{\text {watt }}$ denotes the original (received) echo strength. The composition of $[P]_{\mathrm{dB}}$ is expressed by equation (2) (Matsuoka et al. 2012).

$$
[P]_{\mathrm{dB}}=[S]_{\mathrm{dB}}+[R]_{\mathrm{dB}}-[G]_{\mathrm{dB}}-[L]_{\mathrm{dB}}-[B]_{\mathrm{dB}}
$$

where $\quad[S]_{\mathrm{dB}}=$ influence of instrument on echo strength

$[R]_{\mathrm{dB}}=$ bed reflectivity

$[G]_{\mathrm{dB}}=$ geometric spreading

$[L]_{\mathrm{dB}}=$ dielectric attenuation

\footnotetext{
${ }^{*}$ Corresponding author
} 
$[B]_{\mathrm{dB}}=$ loss due to birefringence (ice fabric anisotropy) Since $[S]_{\mathrm{dB}}$ and $[B]_{\mathrm{dB}}$ can be negligible (Jordan et al., 2018), equation (2) can be simplified as

$$
[P]_{\mathrm{dB}}=[R]_{\mathrm{dB}}-[G]_{\mathrm{dB}}-[L]_{\mathrm{dB}}
$$

Among them, $[R]_{\mathrm{dB}}$ is the one that best reflects the difference between the ice-bedrock interface and the ice-water interface. To recover it, $[G]_{\mathrm{dB}}=2[h+H / \sqrt{\varepsilon}]$ and $[L]_{\mathrm{dB}}=2 N H$ need to be calculated.

where $\quad h=$ height of the plane from the ice surface

$\varepsilon=$ dielectric constant of ice

$H=$ thickness of ice

$N=$ dielectric attenuation rate in ice

Here, $N$ is an unknown variable, other parameters can be obtained from the RES data. To obtain $N$, a popular method is to estimate it by linear model (Wolovick et al., 2013). Then we need to write equation (3) as the following linear form

$$
[P]_{\mathrm{dB}}+[G]_{\mathrm{dB}}=-2 N H+[R]_{\mathrm{dB}}
$$

Thus, we can use $[P]_{\mathrm{dB}}+[G]_{\mathrm{dB}}$ and $H$ of each column (A-scan) of the RES data to perform a linear fitting for equation (4) to obtain the slope $N$ of each A-scan. The above facts are shown in Figure 1, it is a scatter diagram composed of $H$ and corresponding $[P]_{\mathrm{dB}}+[G]_{\mathrm{dB}}$ of a certain A-scan in an echogram in the Antarctica's Gamburtsev Province (AGAP) region. The slope $N$ obtained by fitting the scatter diagram is also marked with a red line.

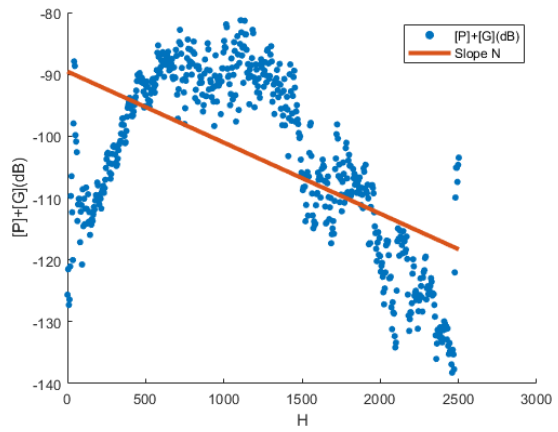

Figure 1. Scatter diagram composed of $H$ and $[P]_{\mathrm{dB}}+[G]_{\mathrm{dB}}$ of a certain A-scan in an echogram in the AGAP region.

Then we take the average of $N$ of all A-scan as the one-way attenuation rate of the echogram. Thus, an echogram has a uniform one-way attenuation rate. Finally, the corrected echo strength $[P]_{\mathrm{dB}}+[G]_{\mathrm{dB}}+[L]_{\mathrm{dB}}$ can be taken as an approximation of $[R]_{\mathrm{dB}}$, which is expressed by $[R]^{\prime} \mathrm{dB}$.

\subsection{Criterion 2: signal thickness}

Signal thickness here refers to the thickness of the brighter region at the basal interface on the echogram. At the ice-water interface, since the electromagnetic wave attenuates very fast after entering water, there will be no echoes, so the signal thickness shall be small. At the ice-bedrock interface, since the electromagnetic wave attenuates relatively slowly in the bedrock, the signal thickness can be large. Therefore, the signal thickness is an effective criterion for judging whether it is water or bedrock under the ice.

The above phenomenon can be seen in Figure 2, which is an example of echogram in AGAP region. It also points out the location of subglacial water and bedrock, and illustrates their different phenomena on signal thickness.

To measure it accurately, we firstly pick the basal interface in each A-scan of the echogram. Then, we use this interface as the central line from which a defined width is used to retain RES data on both sides. The subsequent signal thickness measurement is based on these retained data. Secondly, the retained basal interface echogram in $\mathrm{dB}$ is transformed into a grayscale image with a pixel value range of $[0,255]$, and then the OTSU image binarization algorithm is applied for binarization (Otsu 1975). Thirdly, we count the number of pixels with a pixel value of 1 in each A-scan of the binarized image, and use it as the signal thickness of this A-scan, which is expressed by $T h$. It should be noted that if there is no pixel with the value of 1 in a column, the signal thickness of this column will be set to the known maximum signal thickness.

\subsection{Criterion 3: variance of the signal thickness}

Because the signal attenuation is very fast in water, the signal thickness of the subglacial lake is very small and its difference in the neighbourhood is also small. In contrast, the signal thickness of other types of basal interface can be quite different, since their material compositions may vary significantly and the attenuation rate may be also different. Therefore, this is also a good criterion for distinguishing between lakes and non-lake features. This phenomenon can also be clearly seen in Figure 2 (b).

Implementing this criterion, we only need to calculate the variance of the signal thickness with a certain size of sliding window, and we use $\sigma_{T h}$ to represent this criterion.

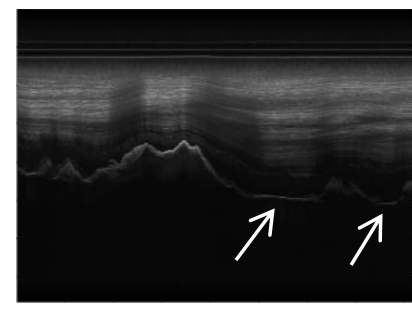

(a)

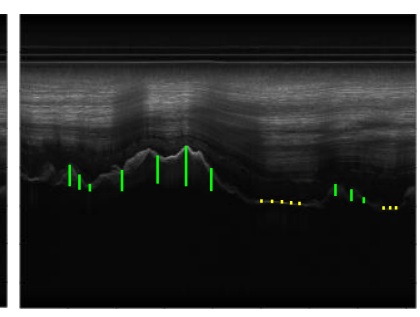

(b)
Figure 2. Example of echogram in AGAP region, it shows the different phenomena of subglacial water and bedrock on the signal thickness and the variance of the signal thickness. (a) the location of two subglacial water (illustrated by white arrows), (b) the different phenomena of subglacial water and bedrock. The green and yellow lines represent the approximate signal thickness of bedrock and subglacial water, respectively. On the whole, the green line is much longer than the yellow line, and the green line is uneven; In contrast, the yellow line is not only very short, but also has no obvious change in the length of a certain subglacial region.

\subsection{Subglacial lake extraction}

To automatically extract subglacial lakes using a single threshold, it is necessary to expand the difference between lakes and non-lakes features as much as possible. Therefore, based on the above three criteria, we define the response value for subglacial lakes using equation (5).

$$
\operatorname{Re}=\left\{[R]_{d B}^{\prime} /\left(T h+\sigma_{T h}\right)\right\}^{2}
$$


where the values of $[R]^{\prime} \mathrm{dB} 、 T h 、 \sigma_{T h}$ are all normalized. The response value is proportional to the likelihood of the subglacial lake. It is worth noting that the fluctuation of the original $R e$ is too strong, if $R e$ is directly threshold processed, a lot of subglacial water in the subglacial lake will be missed. To ensure that some regions in the lake will not be missed after thresholding because of the strong fluctuation of the original $R e$, $R e$ needs to be smoothed at a certain scale. Based on abundant experiments, we set the discrimination threshold to 8 to differentiate subglacial lakes and non-lake.

To better describe the proposed method, a block scheme shows the detailed process of proposed method, as shown in Figure 3.

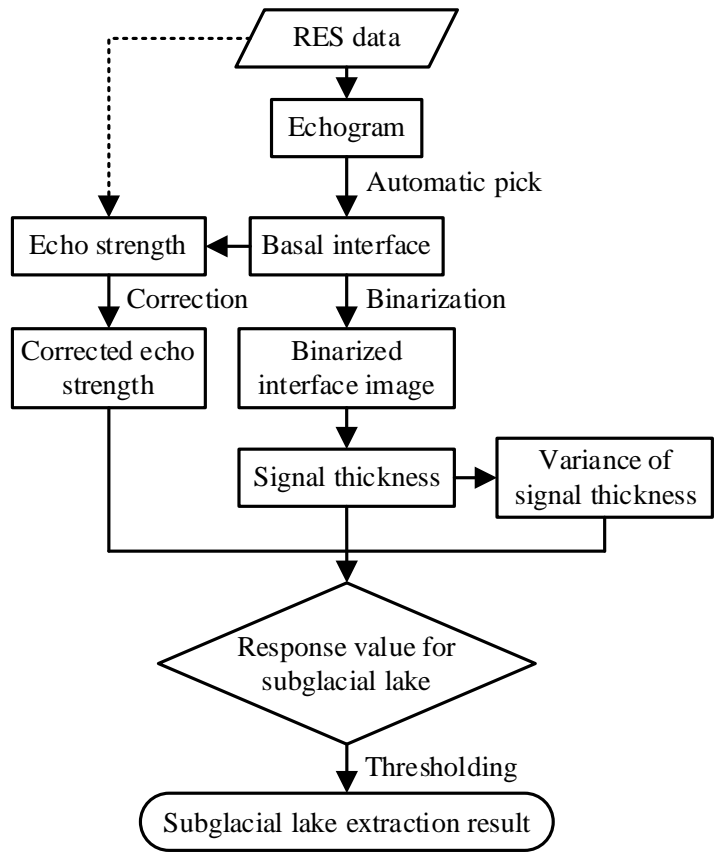

Figure 3. Block scheme of proposed method.

\section{EXPERIMENTAL RESULTS}

\subsection{Experiments with small examples}

As one complete experimental example about the echogram in Figure 2, the detailed experimental results for this example are shown in Figures 4 and 5. Particularly, Figure 4 shows the basal interface grayscale image, the corresponding binarization result of this image, and the three identification criteria value corresponding to the basal interface. It is obviously that the values of two proposed new criteria at subglacial lakes are lower than those in other regions. Figure 5 shows the original and smoothed response values for subglacial lakes, and the subglacial lakes extraction result after applying the threshold.

\section{(a)}

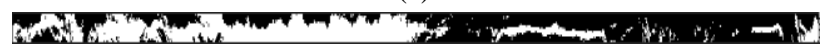

(b)

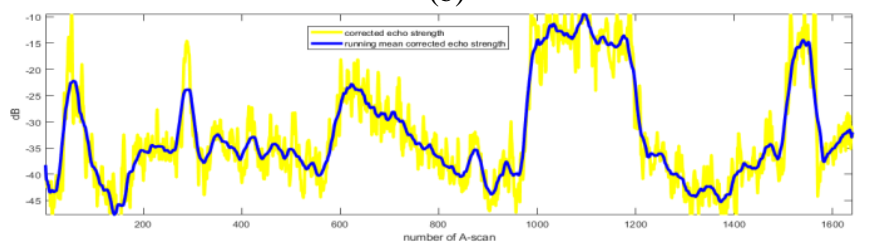

(c)

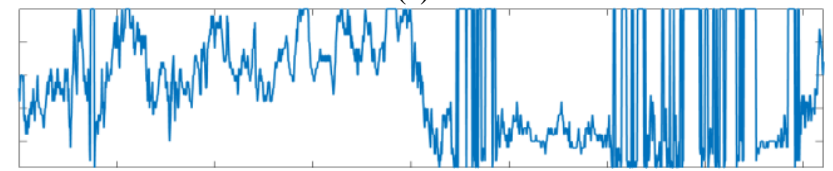

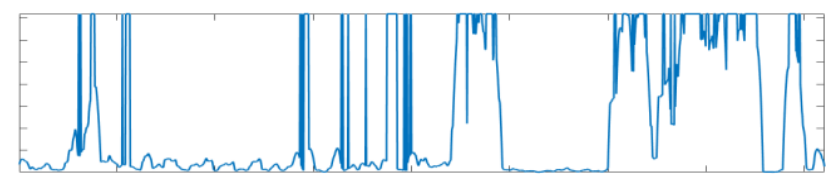

(e)

Figure 4. Experimental results. (a) basal interface grayscale image, (b) binarization result of the grayscale image, (c) corrected echo strength corresponding to the basal interface, (d) signal thickness obtained from the binarization result, (e) variance of the signal thickness.

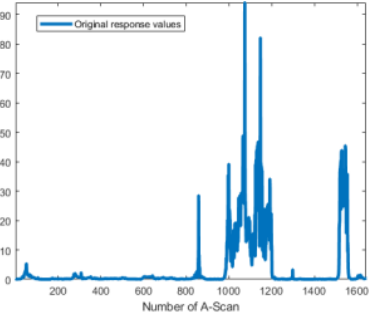

(a)

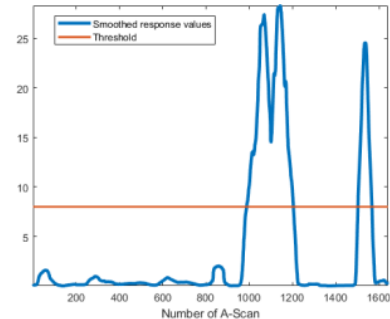

(b)

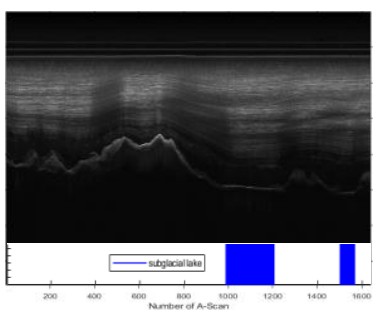

(c)

Figure 5. Experimental results. (a) original response value for subglacial lakes, (b) smoothed response value for subglacial lakes and corresponding threshold, (c) subglacial lakes extraction result.

In order to further prove the effectiveness of the proposed method and increase the sufficiency of the experiment, the experimental results corresponding to several more echograms are shown in Figure 6. These experimental results mainly show three criteria, smoothed subglacial lake response value and the final extraction results. From the experimental results, the locations of subglacial lakes in echograms of different regions can be better extracted by the proposed method. For the echogram without subglacial lake, the whole response value for subglacial lake is very low, which proves the effectiveness of proposed method to a certain extent.

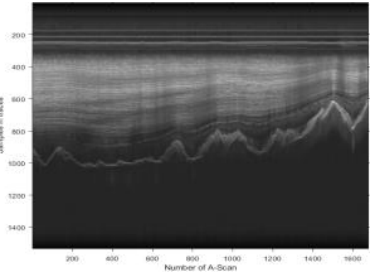

(a1)

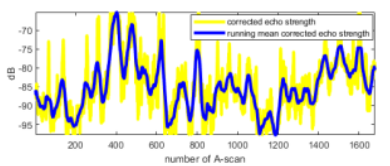

(b1)

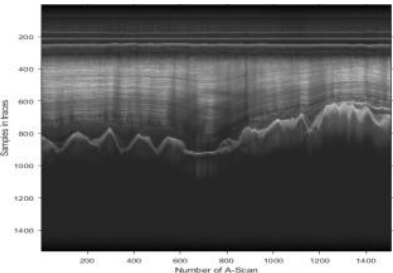

(a2)

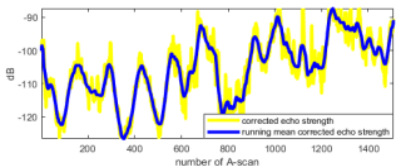

(b2) 


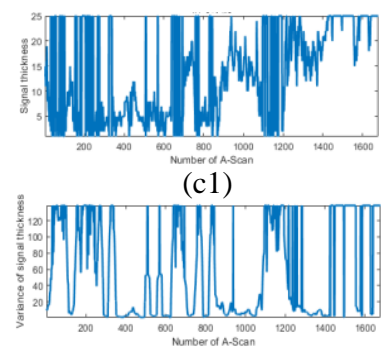

(d1)

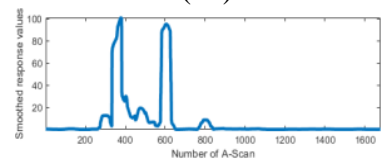

(e1)

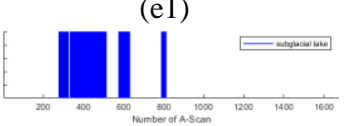

(f1)

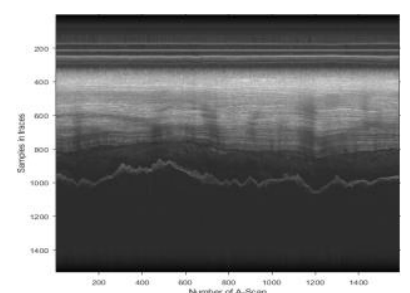

(a3)

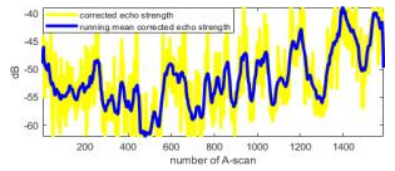

(b3)

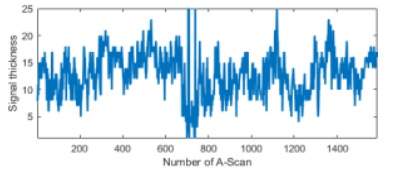

(c3)

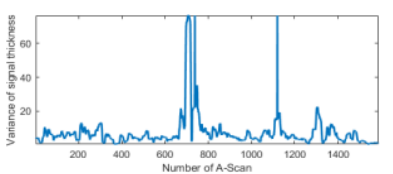

(d3)

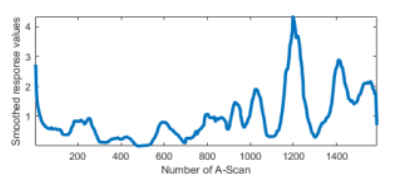

(e3)

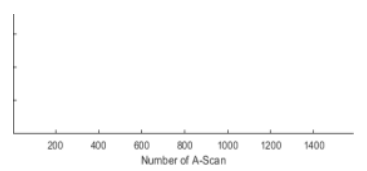

(f3)

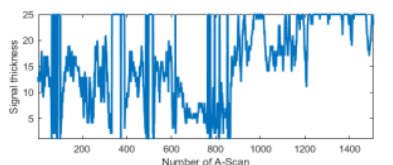

(c2)

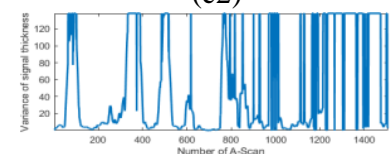

(d2)

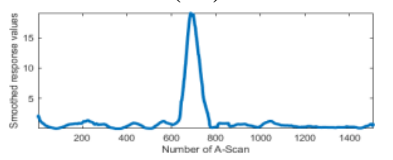

(e2)

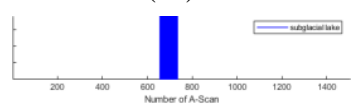

(f2)

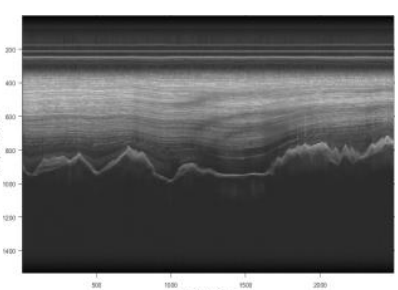

(a4)

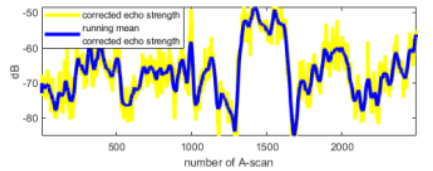

(b4)

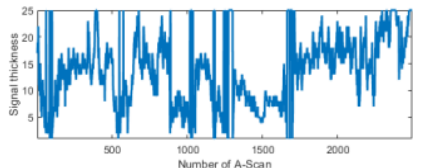

(c4)

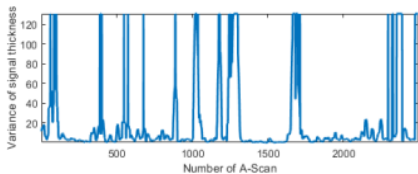

(d4)

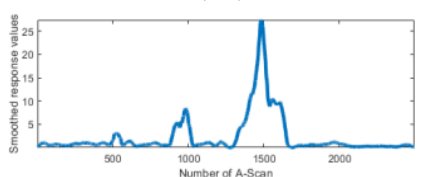

(e4)

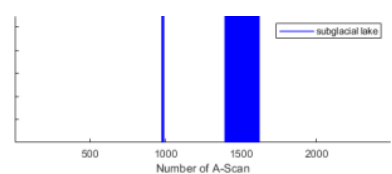

(f4)
Figure 6. Relevant experimental results of other echograms. (a1-a4) Radar echograms, (b1-b4) corrected echo strength corresponding to the basal interface, (c1-c4) signal thickness, (d1-d4) variance of the signal thickness, (e1-e4) smoothed response value for subglacial lakes, (f1-f4) subglacial lakes extraction results.

\subsection{Regional experiments}

The proposed subglacial lake detection method was applied in the AGAP region in Antarctica. Figure 7 shows the location of the AGAP region and its internal flight lines. Figure 8 shows the extraction result of proposed method for the subglacial lake in AGAP region (red box). In order to evaluate our extraction results, the visual interpretation result of subglacial water, as shown in Figure 9, in AGAP region (Wolovick et al., 2013) are compared with our extraction result. It is found that most of subglacial lakes can be successfully detected using proposed method. Some subglacial water and even the wet basal interface may be extracted due to the sensitivity of the threshold.

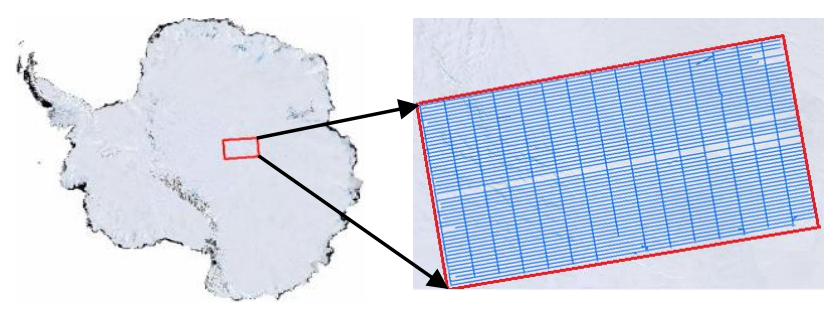

(a)

(b)

Figure 7. Large-scale experimental region and flight lines. (a) AGAP region in Antarctica, (b) flight lines in AGAP region.

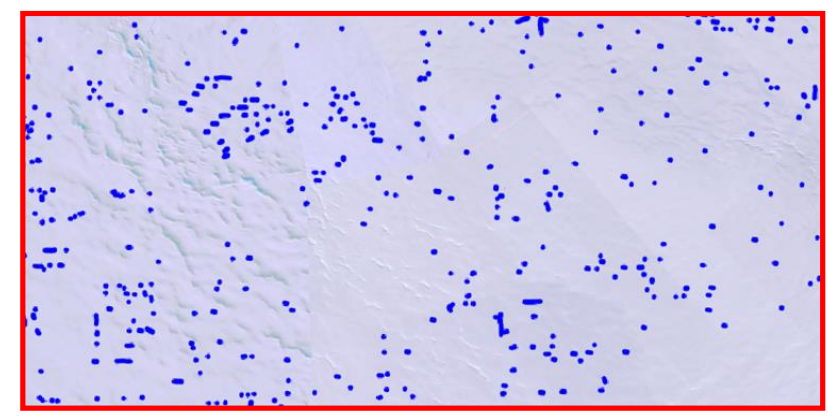

Figure 8. Extraction result of proposed method.

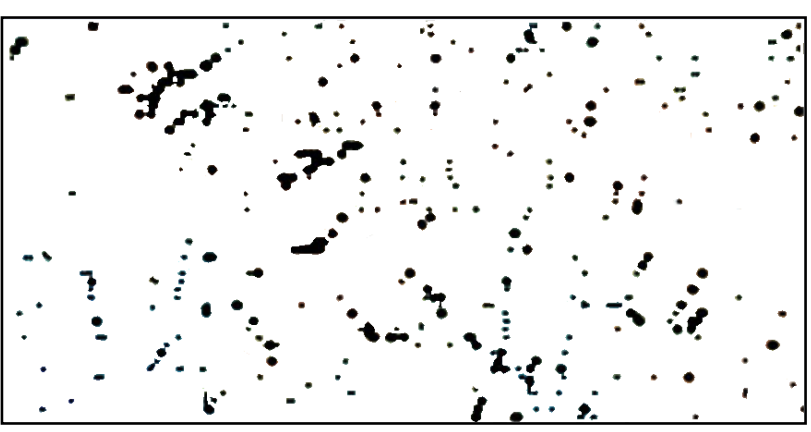

Figure 9. Visual interpretation result in AGAP (Wolovick et al., 2013).

\section{CONCLUSION}

In this paper, a simple image processing technique based on multiple criteria is proposed to automatically differentiate subglacial lake and non-lake features. Through various experiments on RES data, this technique shows a potential in the automated identification of subglacial lakes in the AGAP region. It can be seen from regional experiments that our 
extraction results are highly consistent with visual interpretation result. In the future, the proposed two new criteria can be combined with several traditional criteria, such as bed elevation, roughness, hydraulic head to improve the subglacial lake detection accuracy. Its robustness and the determination of a universal threshold need to be further examined in the whole Antarctica.

In addition, in order to extract and classify whole Antarctic subglacial lakes with high accuracy in the future, it is necessary to develop more promising criteria to depict the characteristics of subglacial water, which will be the focus of our next work.

\section{ACKNOWLEDGEMENTS}

The authors would like to acknowledge the use of data and/or data products from CReSIS generated with support from the University of Kansas. They are also thankful to the anonymous reviewers for their valuable comments that greatly helped in improving this paper. This work was supported by National Science Foundation of China (No. 41801335).

\section{REFERENCES}

Bowling, J.S., Livingstone, S.J., Sole, A.J., Chu, W., 2019: Distribution and dynamics of Greenland subglacial lakes. Nature communications 10(1): 1-11.

Carter, S.P., Blankenship, D.D., Peters, M.E., Young, D.A., Holt, J.W., Morse, D.L., 2007: Radar-based subglacial lake classification in Antarctica. Geochemistry, Geophysics, Geosystems 8(3).

Carter, S.P., Blankenship, D.D., Young, D.A., Holt, J.W., 2009: Using radar-sounding data to identify the distribution and sources of subglacial water: application to Dome C, East Antarctica. Journal of Glaciology 55(194): 1025-1040.

Creyts, T.T., Ferraccioli, F., Bell, R.E., Wolovick, M., Corr, H., Rose, K.C., Frearson, N., Damaske, D., Jordan, T., Braaten, D., Finn, C., 2014: Freezing of ridges and water networks preserves the Gamburtsev Subglacial Mountains for millions of years. Geophysical Research Letters 41(22): 8114-8122.

Diez, A., Matsuoka, K., Jordan, T.A., Kohler, J., Ferraccioli, F., Corr, H.F., Olesen, A.V., Forsberg, R., Casal, T.G., 2019: Patchy lakes and topographic origin for fast flow in the Recovery Glacier system, East Antarctica. Journal of Geophysical Research: Earth Surface 124(2): 287-304.

Dowdeswell, J.A., Siegert, M.J., 2003: The physiography of modern Antarctic subglacial lakes. Global and Planetary Change 35(3-4): 221-236.

Evans, S., 1963: Radio-echo techniques for the measurement of ice thickness. Polar Record 11(73): 406-410.

Gifford, C.M., Agah, A., 2012: Subglacial water presence classification from polar radar data. Engineering Applications of Artificial Intelligence 25(4): 853-868.

Gorman, M.R., Siegert, M.J., 1999: Penetration of Antarctic subglacial lakes by VHF electromagnetic pulses: Information on the depth and electrical conductivity of basal water bodies. Journal of Geophysical Research: Solid Earth 104(B12): 29311-29320.
Ilisei, A.M., Khodadadzadeh, M., Dalsasso, E., Bruzzone, L., 2017: Automatic detection of subglacial lakes in radar sounder data acquired in Antarctica. Proc. SPIE 10427, Image and Signal Processing for Remote Sensing XXIII 1042718.

Ilisei, A.M., Khodadadzadeh, M., Ferro, A., Bruzzone, L., 2018: An automatic method for subglacial lake detection in ice sheet radar sounder data. IEEE Transactions on Geoscience and Remote Sensing 57(6): 3252-3270.

Jordan, T.M., Cooper, M.A., Schroeder, D.M., Williams, C.N., Paden, J.D., Siegert, M.J., Bamber, J.L., 2017: Self-affine subglacial roughness: consequences for radar scattering and basal water discrimination in northern Greenland. The Cryosphere 11(3): 1247-1264.

Jordan, T.M., Williams, C.N., Schroeder, D.M., Martos, Y.M., Cooper, M.A., Siegert, M.J., Paden, J.D., Huybrechts, P., Bamber, J.L., 2018: A constraint upon the basal water distribution and thermal state of the Greenland Ice Sheet from radar bed echoes. The Cryosphere 12(9): 2831-2854.

Langley, K., Kohler, J., Matsuoka, K., Sinisalo, A., Scambos, T., Neumann, T., Muto, A., Winther, J.G., Albert, M., 2011: Recovery Lakes, East Antarctica: Radar assessment of subglacial water extent. Geophysical Research Letters 38(5).

Li, X., Sun, B., Siegert, M.J., Bingham, R.G., Tang, X., Zhang, D., Cui, X., Zhang, X., 2010: Characterization of subglacial landscapes by a two-parameter roughness index. Journal of Glaciology 56(199): 831-836.

Matsuoka, K., MacGregor, J.A., Pattyn, F., 2010: Using englacial radar attenuation to better diagnose the subglacial environment: A review. Proceedings of the XIII Internarional Conference on Ground Penetrating Radar. IEEE: 1-5.

Matsuoka, K., MacGregor, J.A., Pattyn, F., 2012: Predicting radar attenuation within the Antarctic ice sheet. Earth and Planetary Science Letters 359-360: 173-183.

Oswald, G.K.A., Robin, G.Q., 1973: Lakes beneath the Antarctic ice sheet. Nature 245(5423): 251-254.

Oswald, G.K.A., 1975: Investigation of sub-ice bedrock characteristics by radio-echo sounding. Journal of Glaciology 15(73): 75-87.

Oswald, G.K.A., Gogineni, S.P., 2008: Recovery of subglacial water extent from Greenland radar survey data. Journal of Glaciology 54(184): 94-106.

Otsu, N., 1975: A threshold selection method from gray-level histograms. Automatica 11(285-296): 23-27.

Palmer, S.J., Dowdeswell, J.A., Christoffersen, P., Young, D.A., Blankenship, D.D., Greenbaum, J.S., Benham, T., Bamber, J., Siegert, M.J., 2013: Greenland subglacial lakes detected by radar[J]. Geophysical Research Letters 40(23): 6154-6159.

Robin, G.Q., Evans, S., Drewry, D.J., Harrison, C.H., Petrie, D.L., 1970: Radio echo sounding of the Antarctic Ice Sheet. Antarctic Journal of the United States 5:229-232. 
Siegert, M.J., Dowdeswell, J.A., Gorman, M.R., Mcintyre N.F., 1996: An inventory of Antarctic sub-glacial lakes. Antarctic science 8(3): 281-286.

Siegert, M.J., 2000: Antarctic subglacial lakes. Earth-Science Reviews 50(1-2): 29-50.

Siegert, M.J., Taylor, J., Payne, A.J., Hubbard, B., 2004: Macro-scale bed roughness of the Siple coast ice streams in West Antarctica. Earth Surface Processes and Landforms: The Journal of the British Geomorphological Research Group 29(13): 1591-1596.

Taylor, J., Siegert, M.J., Payne, A.J., Hubbard, B., 2004: Regional-scale bed roughness beneath ice masses: measurement and analysis. Computers \& Geosciences 30(8): 899-908.

Wolovick, M.J., Bell, R.E., Creyts, T.T., Frearson, N., 2013: Identification and control of subglacial water networks under Dome A, Antarctica. Journal of Geophysical Research: Earth Surface 118(1): 140-154. 